\title{
The Design of Speed Reducer of Yam Harvester Ditching Chain
}

\author{
Binbin Zhao, Yujing He, Yuan Ren and Yongchang Yu* \\ Henan Agriculture University, Zhengzhou, China \\ * Corresponding author
}

\begin{abstract}
Through the understanding of China's Henan province Chinese yam way of harvest, as well as to the yam harvest machinery manufacturers of visit investigation, in view of the tuber's long $80-100 \mathrm{~cm}$ trenching chain of Chinese yam harvester, optimized design of the reducer. First tractor for the selection, determine the speed of the output shaft, and calculate the ratio of active chain wheel rotation speed to determine the level of gear reducer, and then determine the parameters such as modulus, tooth number of gear, finally according to the mechanical design and processing requirements to design the gear shaft, a driven gear, the best work parameters of the reducer, greatly improve the production efficiency.
\end{abstract}

Keywords-yam; chain ditcher; bevel gear; reducer

\section{INTRODUCTION}

China is an important origin and domestication center of Chinese yam, and there are rich variety of yam $^{[1]}$.The mainly producing areas are the north of Henan Province, in addition Shandong, Hebei, Shanxi and south, southeast China and other regions. Chinese yam is mainly planted in Wen County, Boai County, Qinyang County, Wuzhi County of Henan Province and Huaxian County of Shaanxi Province ,which tuber can reach $80-100 \mathrm{~cm}$ and its diameter can reach $3 \mathrm{~cm}$ or above. It is difficult to harvest because the yam is easily broken and fragile. Nowadays the yam is mostly harvested through artificial digging, however the traditional harvest way The traditional collection is with low-efficiency and high-cost.

The best way to harvest is dig with machines on both sides and manual picking. Chain Ditcher relys on chain cut combination perpendicular to the surface of soil cutting. Chain transmission can effectively prevent skidding and reduce the problem of insufficient torque. Chain transmission also has the advantage of simple integral structure, convenient installation and easy maintenance. Compared to the spiral ditcher, it has a higher efficiency and the ditching width can be adjusted ${ }^{[2]}$. It is a good solution to the problem of yam harvest.

Chain Ditcher includes a power driving part, a frame part, a reducer part, hydraumatic part and ditching chain part. This article mainly expounds the design of reducer. Reduction box is to change the speed and torque output of the tractor to provide proper speed to the chain tooth in order to achieve the best ditching efficiency.

\section{The DESIGN OF PRINCIPLE OF YAM TRENCHER REDUCER}

The normal work of the chain ditcher is inseparable from the five parts of any one. This article is mainly responsible for the design and calculation ditching machine gear box, which function is to change the output speed and torque of the tractor to provide matching chain cutter speed in order to achieve the best ditching efficiency. Reducer design according to the chain ditcher cutter speed setting, draw a furrowing power consumption; Plus walking resistance consumption, determine the overall total power consumption of the machine; To choose suitable tractor from the market, according to the output shaft speed of the tractor and calculate the driving chain wheel rotation speed to determine the level of speed reducer gear ratio. Further determine the modulus, tooth number and other parameters, finalized in accordance with the requirements of mechanical design and processing technology to design the gear shaft, a driven gear, the detailed parameters of the reducer ${ }^{[3]}$.

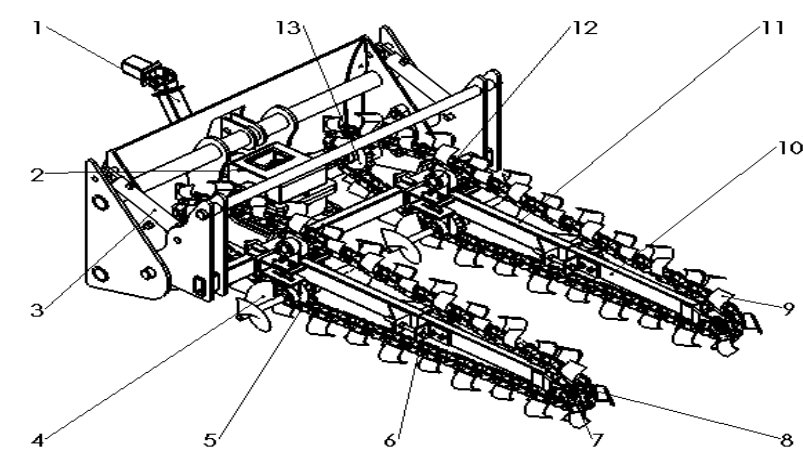

FIGURE I. SIMPLIFIED DIAGRAM OF THE EXECUTIVE BODY OF THE HARVESTER

1. Coupling 2.Transmission 3.Hydraulic Cylinder 4.Screw Arrangement 5 . Screw Arrangement of Soil 6 .Ditching Support Seat Adjustment 7. Driven Sprocket 8.Chain 9.Ditching Circular Blade 10.Rear Supporting Frame 11.Front Connecting Support Bracket 12.Tensioning Sprocket Seat 13.Active Sprocket

\section{SELECTION OF COUPLINGS AND TRACTORS}

\section{A. Selection of Coupling}

Tractor for chain ditcher to provide power, but power output shaft of the tractor and ditching machine input axis does not on an axis, so choose universal coupling. Universal 
coupling to transfer two axis is not on the same axis and two axis exist larger angle, which can realize two axis continuous rotary, reliable transmission of torque, compact structure and transfer efficiency is high. To ensure the synchronization of driving and driven shaft, the general use of the double type to eliminate two shafts are not coaxial single universal coupling cycle speed fluctuation ${ }^{[4]}$. The dynamic coupling with the tractor and the chain trencher are connected by tooth spline and the power transmission is stable.

\section{B. Selection of Tractor}

Chain Ditcher is a tractor rear Pendant. Rely on coupling conversion the tractor power to Chain Ditcher power. We choose Dong Fang Hong-500 wheeled tractor. The maximum output power is $50 \mathrm{kw}$. Power output shaft speed is 540 $720 \mathrm{r} / \mathrm{min}$. In this design, the speed is $540 \mathrm{r} / \mathrm{min}$.

\section{Power Transmission Gear Box Diagram Shown in Figure} II

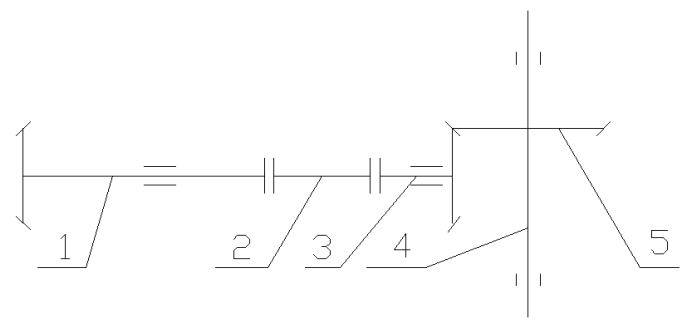

FIGURE II. POWER TRANSMISSION DIAGRAM OF REDUCTION BOX

1.Tractor power output shaft 2.Coupling 3.Gear shaft 4.Driven shaftII5.Driven gear

\section{Speed of Each Shaft}

Power output shaft speed: $\mathrm{n}_{\mathrm{d}}=540 \mathrm{r} / \mathrm{min}$

Rotational speed of I axis: $\mathrm{n}_{1}=540 \mathrm{r} / \mathrm{min}$

Rotational speed of II axis: $\mathrm{n}_{\mathrm{II}}=250 \mathrm{r} / \mathrm{min}$

E. Input and Output Power of Each Axis

Input and output power of the power output shaft:

$$
\mathrm{P}_{\mathrm{d}}=P_{\mathrm{d}}^{\prime}=30 \mathrm{kw}
$$

Input power of I:

$$
\mathrm{P}_{\mathrm{I}}=\mathrm{P}_{\mathrm{d}} \times \eta_{1}
$$

Output power of I:

$$
P_{\mathrm{I}}^{\prime}=\mathrm{P}_{\mathrm{I}} \times \eta_{3}
$$

Input power of II:

$$
\mathrm{P}_{\mathrm{II}}=\mathrm{P}_{\mathrm{I}} \times \eta_{2} \times \eta_{3}
$$

Output power of II:

$$
\mathrm{P}_{\mathrm{II}}{ }^{\prime}=\mathrm{P}_{\mathrm{II}} \times \eta_{3}
$$

\section{F. Input Torque of Each Shaft}

Output torque of tractor:

$$
\mathrm{T}_{\mathrm{d}}=9550 \times \frac{\mathrm{P}_{\mathrm{d}}}{\mathrm{n}_{\mathrm{d}}}
$$

Input torque of axis I:

$$
\mathrm{T}_{\mathrm{I}}=\mathrm{T}_{\mathrm{d}} \times \eta_{1}
$$

Output torque of axis II

$$
T_{\mathrm{II}}=T_{\mathrm{I}} \times \mathrm{i}_{1} \times \eta_{2} \times \eta_{3}
$$

\section{Design of BeVEl Gears AND ShaftS}

\section{A. Design of Bevel Gears}

Select the type of gear, precision grade, material and tooth number. Choose the zero bevel gear transmission, and according to the Gleason system, the driving wheel should turn left, turn right from the left wheel, right ${ }^{[5]}$. The machinery is just for agricultural machinery, and low speed is enough. The selection of small gear material is $40 \mathrm{Cr}$ (quenching) and the hardness is $280 \mathrm{HBS}$. The selection of high gear material is 45 steel (conditioning), and the hardness is $240 \mathrm{HBS}$. The hardness difference between the two is 40HBS. The number of small gear teeth are 14 (check the mechanical manual) ${ }^{[6]}$, and the number of large gear teeth are 30 .

\section{B. Design according to the Contact Strength of Tooth Surface}

1) Small gear indexing circle diameter

$$
\mathrm{d}_{1} \geq \mathrm{ez}_{\mathrm{b}} \mathrm{z}_{\phi} \sqrt[3]{\frac{\mathrm{T}_{1} \mathrm{~K}_{\mathrm{A}} K_{H \beta}}{\mu \sigma_{H \mathrm{lim}}{ }^{2}}}
$$

Circle speed of bevel gear:

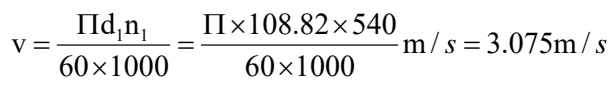

Outer spiral angle: 
$\beta=\arcsin \frac{1}{\mathrm{~d}_{0}}\left[R+\frac{R_{\mathrm{m}}\left(\mathrm{d}_{0} \sin \beta_{\mathrm{m}}-R_{\mathrm{m}}\right)}{R}\right]^{[6]}$

2) The parameters of the gear are arranged as Table I

TABLE I. GEAR PARAMETER LIST

\begin{tabular}{lcc}
\hline Project & Pinion & Gear wheel \\
\hline Profile angle & $20^{\circ}$ & $20^{\circ}$ \\
Addendum coefficient & 1 & 1 \\
Coefficient of tip clearance & 0.19 & 0.19 \\
Bigger end face modules & 8 & 8 \\
Number of teeth & 14 & 30 \\
Reference diameter & $112 \mathrm{~mm}$ & $240 \mathrm{~mm}$ \\
Modification coefficient & 0.3598 & -0.3598 \\
Helix angle of tooth width & $35^{\circ}$ & $35^{\circ}$ \\
Reference cone angle & $24^{\circ} 47^{\prime} 30^{\prime \prime}$ & $65^{\circ} 1230^{\prime \prime}$ \\
Cone torque & $133.548 \mathrm{~mm}$ & $133.548 \mathrm{~mm}$ \\
Tooth width & $33.387 \mathrm{~mm}$ & $33.387 \mathrm{~mm}$ \\
Tooth addendum & $10.8784 \mathrm{~mm}$ & $5.1216 \mathrm{~mm}$ \\
Depth of tooth & $17.552 \mathrm{~mm}$ & $17.552 \mathrm{~mm}$ \\
Tooth dedendum & $6.6736 \mathrm{~mm}$ & $12.4304 \mathrm{~mm}$ \\
Tip diamete & $131.7516 \mathrm{~mm}$ & $244.2952 \mathrm{~mm}$ \\
Dedendum angle & $2.8608^{\circ}$ & $5.3176^{\circ}$ \\
Addendum angle & $5.3176^{\circ}$ & $2.8608^{\circ}$ \\
Tip angle & $30.1095^{\circ}$ & $68.0149^{\circ}$ \\
root angle & $22.0582^{\circ}$ & $59.8905^{\circ}$ \\
External cone height & $119.0922 \mathrm{~mm}$ & $51.3502 \mathrm{~mm}$ \\
\hline Outer spiral angle & $39.7025^{\circ}$ & $39.7025^{\circ}$ \\
\hline Total contact ratio & $15.3284 \mathrm{~mm}$ & $9.7916 \mathrm{~mm}$ \\
\hline
\end{tabular}

C. Design of Shaft I

1) Preliminary calculation of shaft neck

$$
\mathrm{d}_{\min } \geq A_{0} \sqrt[3]{\frac{P}{\mathrm{n}}}
$$

2) Structure design of shaft

Bearing pivot distance:

$$
L^{\prime} \geq 2 a \Rightarrow L^{\prime}>0.7 \mathrm{~d}_{1}^{[8]}=31.5 \mathrm{~mm}
$$

The distance from the Bearing upper end to the inner wall of the base, $\Delta_{3}=3 \mathrm{~mm}$
The distance from the base gear to the end wall, $\Delta_{2}=12 \mathrm{~mm}$

By formula (1)

$$
\mathrm{L}_{4}=\mathrm{n}+\mathrm{e}_{3}+2 \delta+\mathrm{e}
$$

Free length, $\mathrm{n}=14 \mathrm{~mm}$

Thickness of the cup, $\mathrm{e}_{3}=10 \mathrm{~mm}$

Gasket thickness, $\delta=0.5 \mathrm{~mm}$

Bearing end cover thickness, $\mathrm{e}=10 \mathrm{~mm}$

Calculation results: $\mathrm{L}_{4}=35 \mathrm{~mm}$

The length of spline shaft, Reference "mechanical design" formula (2) ${ }^{[9]}$.

$$
\mathrm{p}=\frac{2 \mathrm{~T} \times 10^{3}}{\psi \mathrm{zhL}{ }_{3} \mathrm{~d}_{\mathrm{i}}} \leq[\mathrm{p}]
$$

The structure parameters of the shaft are arranged as follows:

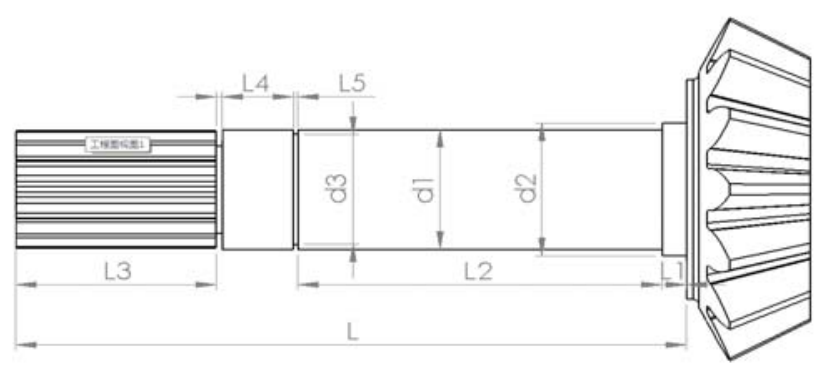

FIGURE III. THE STRUCTURE PARAMETERS OF THE SHAFT

TABLE II. STRUCTURE PARAMETERS OFAXIALI

\begin{tabular}{cc}
\hline Bolster Bearing & Numerical \\
\hline $\boldsymbol{d} \mathbf{1}$ & $45 \mathrm{~mm}$ \\
$\boldsymbol{d} \mathbf{2}$ & $52 \mathrm{~mm}$ \\
$\boldsymbol{d} \mathbf{3}$ & $42.5 \mathrm{~mm}$ \\
$\boldsymbol{L} \mathbf{1}$ & $15 \mathrm{~mm}$ \\
$\boldsymbol{L} \mathbf{2}$ & $84.3 \mathrm{~mm}$ \\
$\boldsymbol{L} 3$ & $85 \mathrm{~mm}$ \\
$\boldsymbol{L} \mathbf{4}$ & $35 \mathrm{~mm}$ \\
$\boldsymbol{L} 5$ & $1.5 \mathrm{~mm}$ \\
$\boldsymbol{L}$ & $222.8 \mathrm{~mm}$ \\
\hline
\end{tabular}

D. Design of Shaft II

1) Schematic Diagram of the Axis As shown in Figure IV 


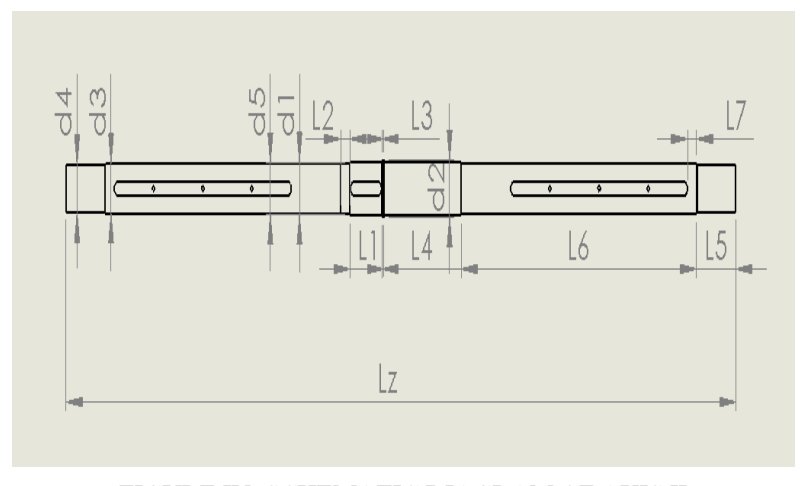

FIGURE IV. SCHEMATIC DIAGRAM OF AXIS II

TABLE III. STRUCTURAL PARAMETERS OF SHAFT

\begin{tabular}{|c|c|}
\hline Bolster Bearing & Numerical \\
\hline$d 1$ & $58 \mathrm{~mm}$ \\
\hline$d 2$ & $68 \mathrm{~mm}$ \\
\hline$d 3$ & $55 \mathrm{~mm}$ \\
\hline$d 4$ & $52 \mathrm{~mm}$ \\
\hline$d 5$ & $57 \mathrm{~mm}$ \\
\hline$L 1$ & $64 \mathrm{~mm}$ \\
\hline$L 2$ & $17 \mathrm{~mm}$ \\
\hline$L 3$ & $3 \mathrm{~mm}$ \\
\hline$L 4$ & $120 \mathrm{~mm}$ \\
\hline$L 5$ & $80 \mathrm{~mm}$ \\
\hline$L 6$ & $500 \mathrm{~mm}$ \\
\hline$L 7$ & $20 \mathrm{~mm}$ \\
\hline$L z$ & $1366 \mathrm{~mm}$ \\
\hline
\end{tabular}

2) Table III Structural Parameters of Shaft

\section{E. Bearing Selection and Installation}

Two reverse mounting cone roller bearing for the shaft I.Bearing type is rolling bearing 30209 GB/T 297-1994.The two bearing allow the shaft to move in one direction. Limit and have better supporting rigidity, which can avoid the phenomenon of card death caused by thermal expansion. Bearing is also tapered roller bearing. Model for rolling bearing is $30211297-1994 \mathrm{~GB} / \mathrm{T}$.

\section{F. Design of Reducer Shell}

The gear box Chain Ditcher mounted on top of the frame,and the working environment is so harsh such as outdoor fields. In order to guarantee the normal work of the gear and have a long service life, the gear adopts the closed type transmission. Therefore the gear box should be designed to ensure the stability and efficient, it can also reduce the accident occurred in the work of gear. The gear box shell are made by low cost and obvious effect of gray iron which is widely used.

\section{CONCLUSION}

This topic is based on actual situation of Chinese yam . In order to solve the problem of Chinese yam harvest, we improved the existing chain ditcher by using double ditching to avoid the traction bias caused by single ditching. The whole machine is more uniform and reasonable in force, and the service life is also increased. Ditch spacing of the ditching machine can be adjusted by the actual situation, more flexible. This enhances its applicability and greatly improves the efficiency of ditching. On the other hand, the reducer adopts spiral bevel gear drive, gear tooth contact, stable transmission, reliable and low noise, mechanical transmission torque, drive larger mechanical torque. This design can meet the actual needs of Chinese yam harvest.

\section{ACKNOWLEDGMENT}

I would like to express my gratitude to all those who helped me during writing of this thesis. My deepest graduate goes to Professor Yongchang $\mathrm{Yu}$, my adviser, for his encourage and guidance. Also thanks to the support of agricultural machinery enterprises in Hennan.

\section{REFERENCES}

[1] Song Junliu, "Progress of Variety Resources and Chemical Constitution in Chinese Yam," Journal of Changjiang Veget Ables, June 2009.

[2] Yuan Jingsheng, Chen Kun. The status quo and characteristics of foreign ditching Technology [J]. Engineering Machinery and Maintenance, June 2011.

[3] Dong Jianjun, Wu Guangwei, Fu Weiqiang, "The Development and Outlook of Agricultural Ditching Machine," Journal of Agricultural Mechanization Research, February 2014.

[4] Pu Lianggui, Ji Minggang, "Mechanical Design," Beijing: Higher Education Press, 2006.

[5] Gao Guodong, Zhao Bing, "The Present Situation of Chinese Yam Industry," March 2007.

[6] Gong Guiyi, "Mechanical Design Course Design Instruction Book," BeiJing: Higher Education Press, 1990.

[7] Cheng Daxian, "Mechanical Design Manual (Fifth Edition)," Beijing: Chemical Industry Press, 2008.

[8] Zhou Kaiqin, "Mechanical parts manual," Beijing: Higher Education Press, 2001.

[9] Wang Shigang, Zhang Xiuqin, Miao Shujie, "Mechanical Design Practice,” Harbin: Harbin Engineering University Press, 2003. 